\title{
Quality of Life in Childhood Epilepsy
}

\author{
NAHID S. AHMED, M.D.; MAHA A. NADA, M.D.; DOAA A. EL'AIDY, M.D. and \\ ABDI HAKIM S. MOHAMMED, M.Sc.
}

The Department of Neurology, Faculty of Medicine, Ain Shams University

\begin{abstract}
Background: Epilepsy is a common chronic neurological condition in developing years that can negatively impact one's physical, social and emotional function.

Aim of Study: The aim of this study was to assess the health-related quality of life (HRQOL) and its predictors in children with epilepsy in Egypt, comparing the relationship between different types of seizures and the HRQOL and increasing the awareness of the importance of assessing physical, psychosocial, and behavioral well-being of children with epilepsy in Egypt.

Patients and Methods: To assess the health-related quality of life (HRQOL) and its predictors in children with epilepsy in Egypt during the period from August 2019 and December 2019. This cross-sectional study was conducted at Ain Shams Neurology Department and included 75 children with epilepsy of 11-18 years. The tools used to assess children's QOL were pediatric QOL questionnaires. Parents' QOL was assessed using SF36 inventory.
\end{abstract}

Results: Children with epilepsy have an affected quality of life according to the PedQOL assessment tool with a mean PedQOL total score $64.4 \pm 6.9$ and ranged from 56.1 to 83.6. Among the different domains of the PedQOL inventory, the results of our study showed that children with epilepsy have got higher scores in the physical and the school domains than in the emotional and social domains. Our sample was drawn from Ain Shams University Hospital. Patients attending this health facility are usually from low to intermediate socioeconomic status which may explain this result.

Conclusion: Epilepsy in children has a great impact on the quality of life of those children particularly on the emotional and social domains. Some antiepileptic drugs like valproic acid have a better effect on the quality of life than others. The higher the children's quality of life the higher is the parents' quality of life. The highly impacted domains of the parents quality of life according to the SF36 questionnaire were role limitation (physical or social), social functioning and mental health domain.

Key Words: Quality of life - Childhood - Epilepsy - Health.

\section{Introduction}

EPILEPSY has a significant emotional impact on parents of affected children, and parental emotional

Correspondence to: Dr. Nahid S. Ahmed, The Department of Neurology, Faculty of Medicine, Ain Shams University stability has been found to be a major predictor of the quality of life (QOL) of the epileptic child [1] It has been associated with significant psychosocial maladjustment in both the affected children and their families [2].

In Austria reported behavioral and emotional problems in $22 \%$ of epileptic children, and studies have described feelings of shame, rejection, fear, worry, low self-esteem, and perception of stigma to be common in children with epilepsy [3]

Increasing attention is being focused on problems experienced by children with epilepsy as a result of stigma, which is associated with poor psychosocial health outcomes and impaired QOL. Epilepsy may interfere with social functioning by limiting educational opportunities, employability, and interpersonal relationships and also increase the risk of death [4].

Childhood epilepsy is an elevated hazard for poor psychological outcomes and impacts on quality of life of children but also has a great sway on family functioning [5]. Children being the highrisk group and in crucial development period during which many cognitive and social skills have to be learned QOL is a significant health outcome to assess children with epilepsy [6] .

The traditional medical goal in the management of epilepsy has focused almost exclusively on seizure control with minimal or no adverse medication effect, whereas the importance of assessing QOL has been ignored [7]. This is particularly true for Egyptian children, where the QOL is probably affected by the social stigma associated with the disease.

\section{Patients and Methods}

This cross sectional observational study was conducted on 75 children with epilepsy at Neurology Department, Ain Shams University during the period from August 2019 and December 2019. The 
study included children within the age group of 11-18 and who were diagnosed with epilepsy at least 6 months ago were included in the present study; while children between ages of 1 to 10 and Mental Retardation (MR) were excluded from the study.

\section{Study methods:}

The data was collected through direct interviews with patients, and their parents "Mother" and collected by the researcher. Demographics are acquired through semi-structured interview and the clinical profiles such as the age of onset, type of seizures, duration of therapy, seizure frequency, etiology of seizures, history of early childhood seizures was obtained from case records, family and drug history.

\section{Definition of $Q O L$ :}

The WHO defines HRQOL in children as children's perception of their position in life in the context of the culture in which they live and in relation to their goals, expectations, and concerns.

It is a broad-ranging concept affected in a complex way by the children's physical health, psychological state, Level of independence, social relationships, and their relationship to features of their environment.

(Guidelines for epidemiologic studies on epilepsy. Commission on Epidemiology and Prognosis, International League against Epilepsy, 1993):

QOL was assessed using Pediatrics' quality of life inventory version 4.0. It is a modular approach to measuring HRQOL in children and adolescents. The Pediatric QOL inventory consists of brief, practical, generic score scales (domains); it contains 23 items suitable for use with healthy school and community populations, and with pediatric populations with acute and chronic Health conditions.

Standard questionnaires, adapted from the Pediatric QOL Questionnaire, were administered to the children and their mothers. The format was translated into Arabic. The 23-item Pediatric QOL Generic Core Scales were designed to measure these core dimensions of health as delineated by WHO and school functioning [8]

In our study, parents' scale was used to assess the children's QOL by asking the mother or care given about any problems the child faced from the following domains: physical (eight items), emotional (five items), Social (five items), and school (five items) functioning domains. The child's physical functioning was measured in terms of problems in walking more than a block, running, participating in sports activities, lifting heavy objects, taking a bath or shower by themselves, doing chores around the house, having aches, and low energy levels.

The child's emotional functioning was measured in terms of feeling afraid or scared, sad, angry, have trouble sleeping, and worry about what will happen to them. The child's social functioning was measured in terms of problems in getting along with other children, getting teased by other children, keeping up when playing with other children, worrying about not being able to do things that other children their age can do, and other children not wanting befriend them. The child's school functioning was assessed in terms of problems in paying Attention in class, forgetting things, keeping up with the school work, missing school because of not being well, and missing school to go to the doctor or hospital.

The scoring system was based on the items of children's QOL. Each question was scored as grades $0,1,2,3$, and 4 . The question is scored 0 when the child or mother answered no problem, scored 1 when the response was almost never a problem, scored 2 if the response was sometimes a problem, scored 3 if the response was often a problem, and finally scored 4 if the response was almost always a problem. Items are transformed to a 0-100 scale as follows: $0=100,1=75,2=50,3=25,4=0$, such that higher scores indicate a better HRQOL.

The mean Total Scale Score is computed as the sum of all the items over the number of items answered on all the scales. The average score for each domain will be obtained by summing up all the scores and dividing the sum by the total number of questions answered. The mean score taken to the nearest whole number was taken as the measure of the impact of epilepsy on the overall HRQOL.

Severity was rated by the clinicians as a score of 0-1 implying no impact, whereas a score of 4 implying the worst impact on the criterion being assessed. Patients with a score of 2 were considered to be mildly affected, whereas patients with a score of 3 were moderately affected, and those with a score of 4 were severely affected.

The Physical Health Summary Score is the same as the Physical Functioning Scale Score. The mean Psychosocial Health summary Score is computed as the sum of the items over the number of items answered in the Emotional, Social, and School Functioning Scales.

\section{Ethical consideration:}

The study was conducted according to the regulation of Ain Shams University ethical and scien- 
tific committee. The privacy of participants and confidentiality of the data was guaranteed during various phases of the study.

\section{Statistical analysis:}

Appropriate statistical analysis was applied according to the available data.

PedsQL total score and domains scores was analysed by different patients' characteristics like: gender, age group, education, type of seizure, level of study, parents' relation, history of the disease, fever in the first month or year of life and duration of epilepsy.

Correlation between children PedsQL total score and parents' quality of life by SF36 was made.

\section{Statistical tests:}

- Data will be described in mean (SD) or median and (IQR) according to their distribution.

- Comparison between groups was made using $t$ test.

- ANOVA and post-hoc Bonferoni test.

- Correlation was made using the Pearson correlation method.

\section{Statistical package:}

SPSS ver. 24.

\section{Results}

\section{Patients' demographics and characteristics:}

The study included 75 children with epilepsy as well as their parents. The mean age for children was $14.11 \pm 1.59$ years with a minimum age of 13 and a maximum of 18 years.Forty-nine $(65.3 \%)$ of children were males and $26(34.7 \%)$ were females.

Education level of children was primary education in $41(54.7 \%)$ of them and secondary level or more in $34(54.3 \%)$.

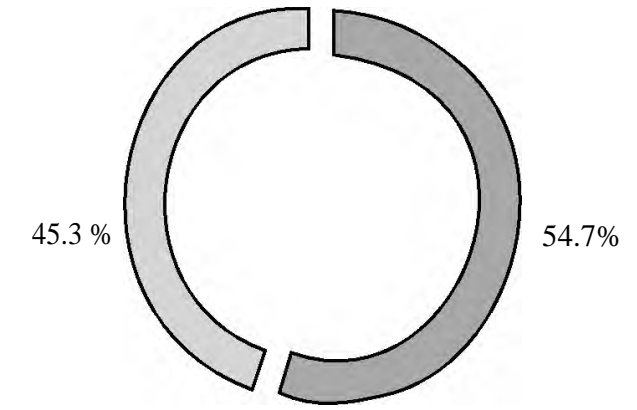

Primary level $\square$ Secondary level or more

Fig. (1): Children's educational level.
In $17(22.7 \%)$ of children the parents were first degree relatives, $48(64.0 \%)$ were second degree relatives and in $10(13.3 \%)$ they were not related.

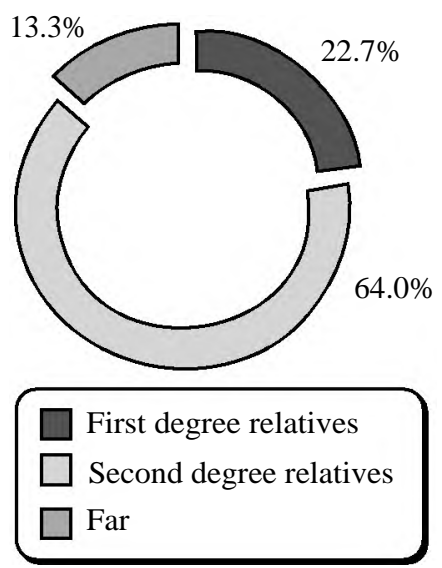

Fig. (2): Parents' relation.

Most children $72(96.0 \%)$ have a positive family history for similar conditions; the majority of them $69(92.0 \%)$ have non-hereditary disorders while 3 $(4.0 \%)$ have hereditary disorder. However, only 3 $(4.0 \%)$ have a negative history of genetic disorders.

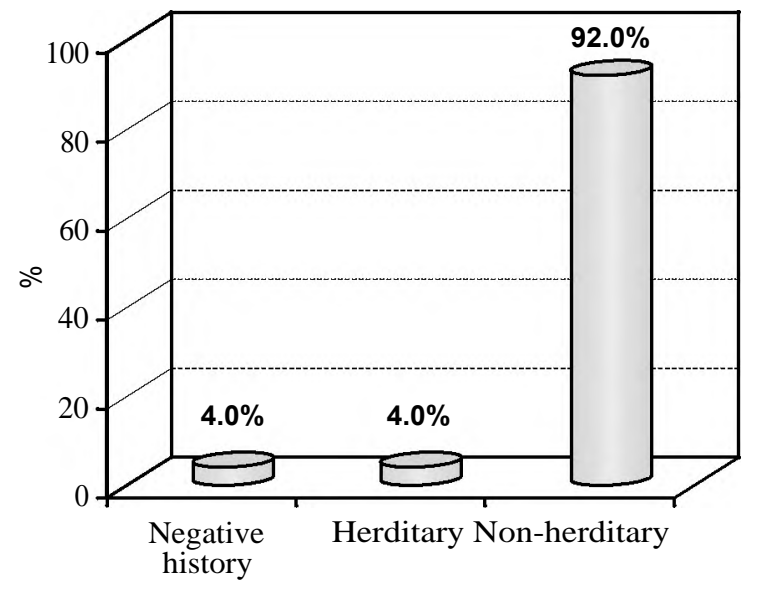

Fig. (3): Family history of similar condition.

Generalized seizures were present in 40 (53.3\%) of children, while partial or focal seizures were in $35(46.7 \%)$.

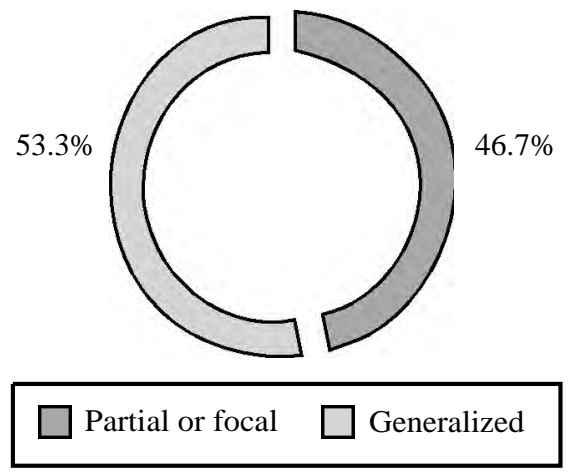

Fig. (4): Type of seizures. 
Carbamazepine was the anti-epileptic drug (AED) used in $35(46.3 \%)$ of children and Levetiracetam was used in 24 (20.0\%). Other AEDs used are shown in the next figure.

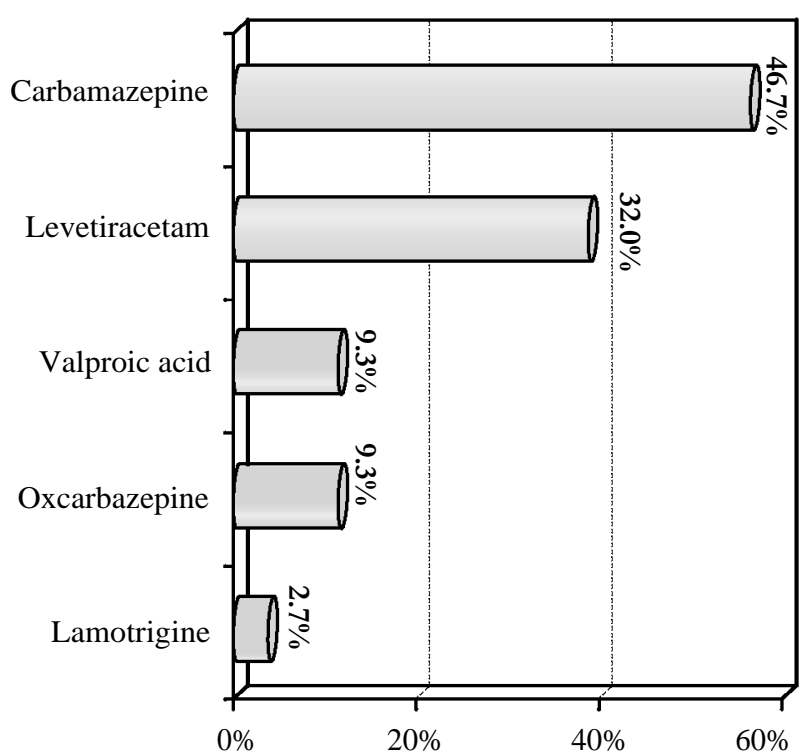

Fig. (5): Anti-epileptic drugs used.

The intelligence quotient (IQ) was less than 90 in $26(34.7 \%)$ of children, from $90-110$ in 41 $(54.7 \%)$ and more than 110 in $8(10.7 \%)$ of children.

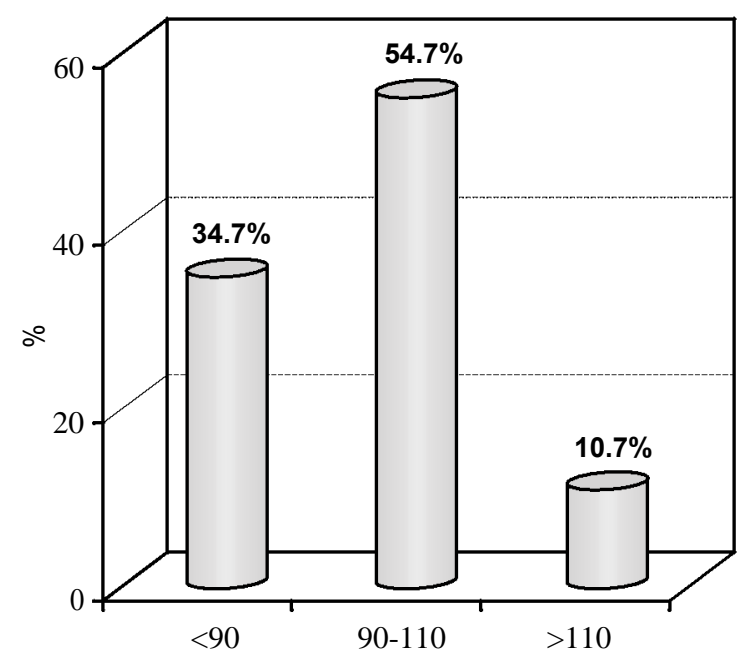

Fig. (6): Frequency of seizures.

Children quality of life according to PedQOL assessment tool:

The mean PedQOL total score was $64.4 \pm 6.9$ with a minimum score of 56.1 and a maximum of 83.6.

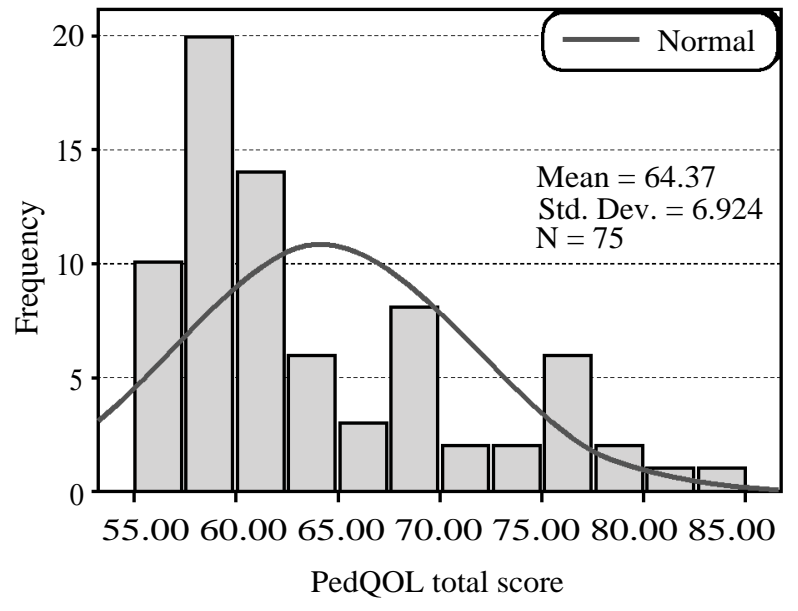

Fig. (7): PedQOL total score frequency distribution.

Table (1): PedQOL total score descriptive statistics.

\begin{tabular}{lc}
\hline & Statistic \\
\hline Mean & 64.4 \\
95\% Confidence Interval for Mean: & \\
$\quad$ Lower Bound & 62.8 \\
$\quad$ Upper Bound & 66.0 \\
Median & 62.2 \\
Variance & 47.9 \\
Std. Deviation & 6.9 \\
Minimum & 56.1 \\
Maximum & 83.6 \\
Range & 27.5 \\
Interquartile Range & 9.5 \\
\hline
\end{tabular}

The children have got higher scores in the physical and the school domains than in the emotional and social domains.

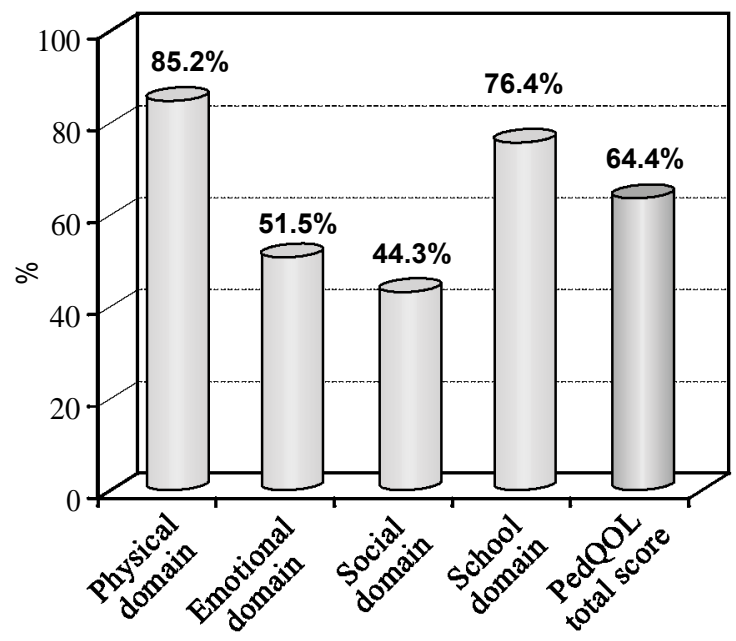

Fig. (8): PedQOL domains and total scores. 
Table (2): PedQOL domain score descriptive statistics.

\begin{tabular}{|c|c|c|c|c|c|}
\hline & \multicolumn{2}{|c|}{ N Minimum } & Maximum & Mean & \multirow{2}{*}{$\begin{array}{c}\begin{array}{c}\text { Std. } \\
\text { Deviation }\end{array} \\
2.4\end{array}$} \\
\hline Physical domain & 75 & 78.1 & 93.8 & 85.2 & \\
\hline $\begin{array}{c}\text { Emotional } \\
\text { domain }\end{array}$ & 75 & 35 & 90 & 51.5 & 13.5 \\
\hline Social domain & 75 & 25 & 90 & 44.3 & 15.9 \\
\hline School domain & 75 & 75 & 80 & 76.4 & 2.3 \\
\hline $\begin{array}{l}\text { PedQOL } \\
\text { total score }\end{array}$ & 75 & 56.1 & 83.6 & 64.4 & 6.9 \\
\hline
\end{tabular}

Factors affecting the children quality of live:

Further statistical analyses were done to investigate the factors that may predict the PedQOL total score. The following factors were studied: gender, educational level, consanguinity, history of genetic disorders, type of seizures, duration of epilepsy, frequency of seizures, duration of seizures, IQ and AEDs.

Among all these factors, only, parents' relation, duration of seizures, IQ and AEDs have an impact on the PedQOL total score ( $p$-values $<0.05$ ), as shown in the next table.

Table (3): Factors affecting the total PedQOL score.

\begin{tabular}{|c|c|c|c|c|c|c|}
\hline Parameter & & $\mathrm{N}$ & $\begin{array}{l}\text { Mean total } \\
\text { PedQOL score }\end{array}$ & SD & $p$-value & \\
\hline \multirow[t]{2}{*}{ Gender } & Male & 49 & 63.8 & 7.0 & \multirow[t]{2}{*}{0.296} & \multirow[t]{2}{*}{$t$-test } \\
\hline & Female & 26 & 65.5 & 6.8 & & \\
\hline \multirow[t]{2}{*}{ Educational level } & Primary level & 41 & 64.5 & 7.3 & \multirow[t]{2}{*}{0.817} & \multirow[t]{2}{*}{$t$-test } \\
\hline & Secondary level or more & 34 & 64.2 & 6.5 & & \\
\hline \multirow[t]{3}{*}{ Consanguinity } & First degree relatives & 17 & 67.6 & 7.9 & \multirow[t]{3}{*}{0.004} & \multirow[t]{3}{*}{ ANOVA } \\
\hline & Second degree relatives & 48 & 62.4 & 5.8 & & \\
\hline & Far & 10 & 68.2 & 7.2 & & \\
\hline \multirow[t]{3}{*}{ History of similar conditions } & Negative & 3 & 68.5 & 6.9 & \multirow[t]{3}{*}{0.493} & \multirow[t]{3}{*}{ ANOVA } \\
\hline & Hereditary & 3 & 66.4 & 8.2 & & \\
\hline & Non-hereditary & 69 & 64.1 & 6.9 & & \\
\hline \multirow[t]{2}{*}{ Type of seizures } & Partial or focal & 35 & 64.0 & 6.4 & \multirow[t]{2}{*}{0.700} & \multirow[t]{2}{*}{$t$-test } \\
\hline & Generalized & 40 & 64.7 & 7.4 & & \\
\hline \multirow[t]{3}{*}{ Duration of epilepsy } & $<3$ years & 31 & 65.6 & 7.6 & \multirow[t]{3}{*}{0.329} & \multirow[t]{3}{*}{ ANOVA } \\
\hline & $3-5$ years & 31 & 64.0 & 7.1 & & \\
\hline & $>5$ years & 13 & 62.3 & 4.0 & & \\
\hline \multirow[t]{2}{*}{ Frequency of seizures } & $<3$ per month & 31 & 63.5 & 6.1 & \multirow[t]{2}{*}{0.359} & \multirow[t]{2}{*}{$t$-test } \\
\hline & $>$ or equal to 6 per month & 44 & 65.0 & 7.4 & & \\
\hline \multirow[t]{3}{*}{ Duration of seizures } & $<3$ minutes & 37 & 67.5 & 6.9 & \multirow[t]{3}{*}{0.000} & \multirow[t]{3}{*}{ ANOVA } \\
\hline & 3-4 minutes & 20 & 61.3 & 5.6 & & \\
\hline & $>4$ minutes & 18 & 61.3 & 5.5 & & \\
\hline \multirow[t]{3}{*}{ IQ } & $<90$ & 26 & 66.9 & 7.9 & \multirow[t]{3}{*}{0.033} & \multirow[t]{3}{*}{ ANOVA } \\
\hline & $90-110$ & 41 & 62.5 & 5.3 & & \\
\hline & $>110$ & 8 & 65.7 & 8.8 & & \\
\hline \multirow[t]{5}{*}{ AEDs } & Carbamazepine & 35 & 64.2 & 7.0 & \multirow[t]{5}{*}{0.025} & \multirow[t]{5}{*}{ ANOVA } \\
\hline & Lamotrigine & 2 & 65.5 & 6.2 & & \\
\hline & Levetiracetam & 24 & 63.1 & 6.1 & & \\
\hline & Oxcarbazepine & 7 & 61.4 & 4.0 & & \\
\hline & Valproic acid & 7 & 72.0 & 8.0 & & \\
\hline
\end{tabular}

1- PedQOL total score according to parents' relation:

The ANOVA test showed that the mean PedQOL total score was different according to the parents' relation $(p=0.004)$. Post-hoc tests showed that the mean PedQOL total score is significantly ( $p=0.037)$ higher in the children whose parents' relations are far 68.2 \pm 7.2 than those whose parents are related 62.4 \pm 5.8 . Also, The mean PedQOL total score is significantly $(p=0.019)$ higher in the children whose parents are first degree relatives $67.6 \pm 7.9$ than those whose parents are second degree relatives $62.4 \pm 5.8$. 


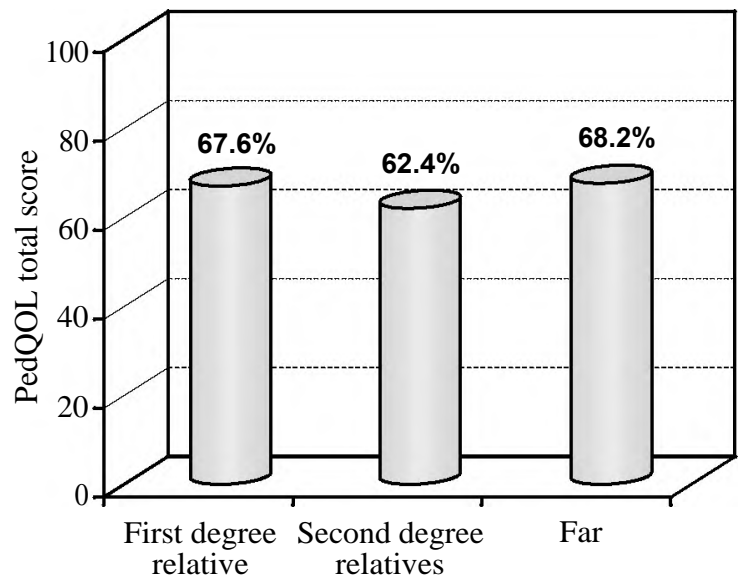

Fig. (9): PedQOL total score according to parents' consanguinity.

\section{2- PedQOL total score according to duration of seizures:}

The ANOVA test showed that the mean PedQOL total score was different according to the duration of seizure $(p<0.001)$. Post-hoc tests showed that the mean PedQOL total score is significantly higher in the children whose duration of seizures is less than 3 minutes $67.5 \pm 6.9$ than those whose duration of seizures is $3-4$ minutes $61.3 \pm 5.6(p=0.002)$ or more than 4 minutes $61.3 \pm 5.5(p=0.003)$.

\section{3-PedQOL total score according to children IQ:}

The ANOVA test showed that the mean PedQOL total score was different according to the IQ of children ( $p$ 0.033). Post-hoc tests showed that the mean PedQOL total score is significantly $(p=0.033)$ higher in the children whose IQ $<90(66.9 \pm 7.9)$ than those whose IQ from 90-110 (62.5 \pm 5.3$)$.

\section{4- PedQOL total score according to AEDs used:}

The ANOVA test showed that the mean PedQOL total score was different according to the AED used ( $p$ 0.025). Post-hoc tests only showed that the mean PedQOL total score is significantly $(p=0.024)$ higher in the children who are on valproic acid 72.0 \pm 8.0 than those on levetiracetam $63.1 \pm 6.1$. Also, the mean PedQOL total score is significantly $(p=0.035)$ higher in the children who are on valproic acid $72.0 \pm 8.0$ than those on oxcarbazepine $61.4 \pm$ 4.0.

Parents' QOL according to SF36 questionnaire and its relation to the children quality of live:

There is a highly significant $(p=0.001)$ moderate $(r=0.39)$ positive correlation between the total score of parents QOL according to SF36 tool and children QOL according to PedQOL total score. The higher the children score the higher is the parents score.

Table (4): PedQOL and parents QOL.

\begin{tabular}{llccccc}
\hline Parents QOL & PedQOL & $\begin{array}{c}\text { Physical } \\
\text { domain }\end{array}$ & $\begin{array}{c}\text { Emotional } \\
\text { domain }\end{array}$ & $\begin{array}{c}\text { Social } \\
\text { domain }\end{array}$ & $\begin{array}{c}\text { School } \\
\text { domain }\end{array}$ & $\begin{array}{c}\text { Total } \\
\text { score }\end{array}$ \\
\hline Physical functioning & $r$ & -0.23 & -0.19 & -0.18 & 0.07 & -0.21 \\
& $p$-value & 0.052 & 0.096 & 0.124 & 0.893 & 0.063 \\
Role limitation (Physical) & $r$ & $0.24 *$ & $0.32 * *$ & $0.56^{* *}$ & $0.61 * *$ & $0.55^{* *}$ \\
& $p$-value & 0.037 & 0.006 & 0.000 & 0.000 & 0.000 \\
Pain & $r$ & -0.15 & -0.20 & -0.00 & -0.01 & -0.11 \\
General health perception & $p$-value & 0.211 & 0.088 & 0.995 & 0.916 & 0.342 \\
Energy/vitality & $r$ & -0.03 & -0.09 & -0.13 & 0.10 & -0.11 \\
Social functioning & $p$-value & 0.831 & 0.446 & 0.262 & 0.377 & 0.335 \\
Role limitation (social) & $r$ & -0.02 & -0.19 & -0.12 & -0.30 & -0.19 \\
Mental health & $p$-value & 0.878 & 0.100 & 0.299 & 0.008 & 0.103 \\
& $r$ & 0.10 & $0.40 * *$ & $0.33 * *$ & $0.53 * *$ & $0.43 * *$ \\
\hline Total score & $p$-value & 0.408 & 0.000 & 0.004 & 0.000 & 0.000 \\
& $r$ & $0.28 *$ & $0.41 * *$ & $0.67 * *$ & $0.63 * *$ & $0.66^{* *}$ \\
& $p$-value & 0.017 & 0.000 & 0.000 & 0.000 & 0.000
\end{tabular}




\section{Discussion}

The activity of the neuron chains is coordinated by electrical and chemical signals. People with epilepsy have recurrent bursts of abnormal electrical activity in the brain. This change in brain activity leads to an epileptic seizure. An epileptic seizure can take a number of different forms - it can cause changes in a person's body movements, awareness, behaviour, emotions or senses (such as taste, smell, vision or hearing). Usually a seizure lasts for only a few seconds or minutes and then the brain activity returns to normal. Having one seizure does not necessarily mean that someone has epilepsy [9]

Epilepsy is not a single condition: In the NICE guideline, the term 'the epilepsies' is used to show that not just one but many brain conditions can result in recurrent epileptic seizures. Some epilepsies start in childhood, some start in young people or in adults, while others start in older people; some last for only a short time and others last for a lifetime; some have little impact on a person's life and others can have a major effect on a person's ability to function and live their daily life [10]

This study was undertaken to assess the healthrelated quality of life (HRQOL) and its predictors in children with epilepsy in Egypt, comparing the relationship between different types of seizures and the HRQOL and increasing the awareness of the importance of assessing physical, psychosocial, and behavioral well-being of children with epilepsy in Egypt.

This study assessed the health-related quality of life and its predictors in children with epilepsy, comparing the relationship between different types of seizures and health-related quality of life in Egypt.

This cross-sectional study was be conducted at Neurology department OPC Ain Shams University Hospital with 75 patients.

The results of this cross-sectional study showed that children with epilepsy have an affected quality of life according to the PedQOL assessment tool with a mean PedQOL total score $64.4 \pm 6.9$ and ranged from 56.1 to 83.6.

Pediatric epilepsy is associated with various comorbidities. It is well-known that children with epilepsy have a compromised health-related QOL and may be affected across physical, psychological, social, and educational domains [11]

Karnavat et al. [11] investigated the QOL in children with epilepsy in both the private and public sectors in India. The study included data drawn from 601 from private and public setting children and adolescents with epilepsy and at least one parent.

The Karnavat and his co-workers [11] study reported that the overall PedQOL score was 67.21 \pm 29.391 and $78.66 \pm 9.161$ in private and public settings, respectively; which is more or less near to that in our study.

Moreover, the PedQOL total score in our study was comparable to a similar study done in Serbia using the same scale [12]

The study of Jovanovic et al. [12] includeda total of 75 Serbian children with epilepsy and at least one parent. The PedQOL Inventory was utilized to assess the health-related QOL. Also, the study used the Adverse Event Profile to assess the presence and severity of the adverse effects of epilepsy drugs.

Moreover, this is also in agreement with the results of the Serbian study which showed higher score in the physical domain [12].

Among the different domains of the PedQOL inventory, the results of our study showed that children with epilepsy have got higher scores in the physical and the school domains than in the emotional and social domains. Our sample was drawn from Ain Shams University hospital. Patients attending this health facility are usually from low to intermediate socio-economic status which may explain this result.

Similar to the results of our current research study, children with epilepsy have got a higher score in QOL in the physical domain more than the psychosocial domain in the study of Karnavat et al. [11]

In the current study, further statistical analyses were done to detect factors that may predict the QOL. Among all the investigated factors that may predict the PedQOL total score, only, consanguinity, duration of seizures, IQ and AEDs have an impact on the PedQOL total score.

However, among all the investigated factors that may predict the PedQOL total score, Karnavat et al. (2018) showed that only parents education, type of seizure, age at onset of epilepsy in years, seizure frequency, IQ have an impact on the PedQOL total score [11]

In our current study, the ANOVA test showed that the mean PedQOL total score was different according to the IQ of children. Post-hoc tests 
showed that the mean PedQOL total score is significantly higher in the children whose IQ $<90$ than those whose IQ from 90-110.

In contrast to the results of our study, Karnavat et al. [11] showed that the mean PedQOL total score was significantly higher in the children whose IQ $>90$ than those whose IQ $<90$.

The ANOVA test in our study showed that the mean PedQOL total score was different according to the parents' relation. The mean PedQOL total score is significantly higher in the children whose parents' relation are far than those whose parents are related (second degree). Also, the mean PedQOL total score is significantly higher in the children whose parents are first degree relatives than those whose parents are second degree relatives. It seems that the closer is the relation between parents, the lower the QOL according to the PedQOL total score.

Certain AED can improve the QOL more than others. The results of this current research showed that the mean PedQOL total score was different according to the AED used. The mean PedQOL total score is significantly higher in the children who are on valproic acid than those on levetiracetam. Also, the mean PedQOL total score is significantly higher in the children who are on valproic acid than those on oxcarbazepine.

Jovanovic et al. [12] too noted that AEDs played a huge impact on the psychosocial functioning of children in their study and consequently on the total PedQOL score. Most probably that was due to the drug adverse event as well as the ability of the drug to control the condition.

Childhood epilepsy has a severe impact on parental QOL and psychological health, and recognition of possible correlations between parental QOL and background variables will be helpful to improve parental QOL.

According to the results of this current crosssectional study, there is a highly significant moderate positive correlation between the total score of parents QOL according to SF36 tool and children QOL according to PedQOL total score.

The higher the children score the higher is the parents score. The highly impacted domains of the parents QOL according to the SF36 questionnaire were role limitation (physical or social), social functioning and mental health domain.

In accordance with our study, the lower QOL scores in SF-36 of parents of children with epilepsy have been reported in the study of Lv et al. [13] which was conducted to assess the impact of children epilepsy on their parental quality of life and psychological health. Also, they investigated the possible correlations between parental QOL and background variables as well as parental anxiety and depression. They included 263 parents having an epileptic child and 270 parents having a healthy child. Both groups were comparable in their demographic and baseline characteristics. They used the SF-36 Questionnaire, Zung Depression Scale and Zung Anxiety Scale in all parents.

Of course, epilepsy in children impacts parents' QOL in a significant way [14] . Furthermore, the condition is associated with a range of cognitive and behavioral troubles that are often unrecognized and under-treated and have a tremendous impact on Health-Related QOL $[15,16]$.

Difficulties in school like academic underachievement or attendance problems, which may also affect the parents' well-being [17] .

Also, families of children with epilepsy have been found to experience significantly more anxiety, stress, and limitations in their family life than other families (Jovanovic et al., 2015).

One of the limitations in the current study is the convenience sampling technique used, which can lead to sampling bias as we used an hospitalbased samples may not represent all childhood epilepsy populations.

Another limitation is that the parents who visited the hospital were usually in a low to intermediate socioeconomic state.

Number of samples to view size 75 .

\section{Conclusion:}

Epilepsy in children has a great impact on the quality of life of those children particularly on the emotional and social domains. Some antiepileptic drugs like valproic acid have a better effect on the quality of life than others. The higher the children's quality of life the higher is the parents' quality of life. The highly impacted domains of the parents quality of life according to the SF36 questionnaire were role limitation (physical or social), social functioning and mental health domain.

\section{References}

1- CONNOLLY A.M., NORTHCOTT E., CAIRNS D.R., MCINTYRE J., CHRISTIE J., BERROYA A., et al.: Quality of life of children with benign rolandic epilepsy. Pediatr. Neurol., 35: 240-245, 2006. 
2- HØIE B., SOMMERFELT K., WAALER P.E., ALSAKER F.D., SKEIDSVOLL H. and MYKLETUN A.: Psychosocial problems and seizure-related factors in children with epilepsy. Dev. Med. Child Neurol., 48: 213-219, 2006.

3- de SOUZA E.A.P. and SALGADO P.C.B.: A psychosocial view of anxiety and depression in epilepsy. Epilepsy Behav., 8: 232-238, 2006.

4- MacLEOD J.S. and AUSTIN J.K.: Stigma in the lives of adolescents with epilepsy: A review of the literature. Epilepsy Behav., 4: 112-117, 2003.

5- MALHI P. and SINGHI P.: Correlates of quality of life with epilepsy. Indian J. Pediatr., 72: 131-5, 2005.

6- TAYLOR J., JACOBY A., BAKER G.A. and MARSON A.G.: Self-reported and parent-reported quality of life of children and adolescents with new-onset epilepsy. Epilepsia, 52: 1489-98, 2011.

7- RONEN G.M., STREINER D.L. and ROSENBAUM P.: Health-related quality of life in childhood epilepsy: Moving beyond 'seizure control with minimal adverse effects'. Health Qual Life Outcomes, 1: 36, 2003.

8- VARNI J.W., SEID M. and KURTIN P.S.: PedsQL 4.0 Reliability and validity of the Pediatric Quality of Life Inventory version 4.0 Generic Core Scales in healthy and patient populations. Med. Care, 39: 800-812, 2001.

8- VARNI J.W., SEID M. and KURTIN P.S.: PedsQL 4.0: Reliability and validity of the Pediatric Quality of Life Inventory version 4.0 Generic Core Scales in healthy and patient populations. Med. Care, 39: 800-812, 2001.

9- NICE 2012. The Epilepsies. The diagnosis and management of the epilepsies in adults and children in primary and secondary care. London: Published by the National Clinical Guideline Centre at The Royal College of Physi- cians; 2012. http://www.nice.org.uk/guidance/cg137 Accessed 24 Sep 2014.

10- National Institute for Health and Clinical Excellence (NICE). (2012). The epilepsies: The diagnosis and management of the epilepsies in adults and children in primary and secondary care (update). (Clinical Guideline 137.). Found at: http://guidance.nice.org.uk/CG137.

11- KARNAVAT P.K., HEGDE A.U. and KULKARNI S.: Quality of Life in Children with Epilepsy in Private and Public Tertiary Care Centers in India.International Journal of Epilepsy, 5 (01): 028-37, 2018.

12- JOVANOVIC M., JOCIC-JAKUBI B., STEVANOVIC D.: Adverse effects of antiepileptic drugs and quality of life in pediatric epilepsy. Neurol. India, 63 (3): 353-359, 2015.

13- LV R., WU L., JIN L., LU Q., WANG M., QU Y. and LIU H.: Depression, anxiety and quality of life in parents of children with epilepsy. Acta. Neurologica Scandinavica, 120: 335-341, 2009.

14- THURMAN D.J., BEGHI E., BEGLEY C.E., et al.: Standards for epidemiologic studies and surveillance of epilepsy. Epilepsia, 52 (Suppl. 7): 2-26, 2011.

15- OTT D., SIDDARTH P., GURBANI S., et al.: Behavioral disorders in pediatric epilepsy: Unmet psychiatric need. Epilepsia, 44: 591-7, 2003.

16- REILLY C., ATKINSON P., DAS K.B., et al.: Factors associated with quality of life in active childhood epilepsy: A population-based study. Eur. J. Paediatr. Neurol., 19: 308-313, 2015.

17- AGUIAR B.V., GUERREIRO M.M. and McBRIAN D.: Seizure impact on the school attendance in children with epilepsy. Seizure, 16: 698-702, 2007.

\section{جودة الحياة فى الأطفال المصابين بالصرع}

المقدمة: يعتبر الصرع أحد الصالات العصيية المزمنة الشائعة التى قد تحدث خلال فترة النمو ويمكن أن تؤثثر سلباً على الوظائف الجسدية

والاجتماعية والوجدانية.

هدف العمل: تقييم نوعية الحياة المتعلقة بالصحة (HRQOL) وعوامل التتبؤ الخاصة بها لدى الأطفال المصابين بالصرع في مصر خلال

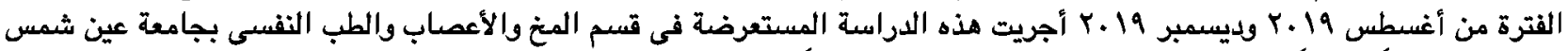

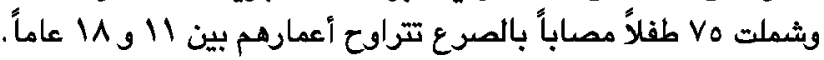

الأدوات المستخدهة: لتقييم جودة الحياة للأطفال كانت استبيانات جودة الحياة للأطفال. تم تقييم جودة الحياة للوالدين باستخدام قائمة

استبيان SF36.

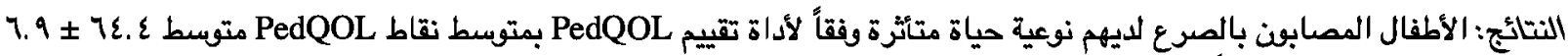

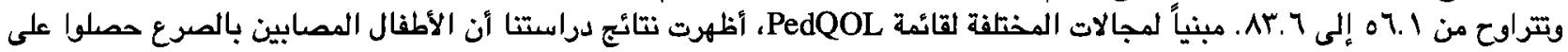

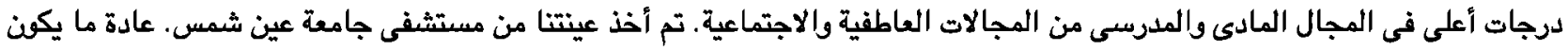

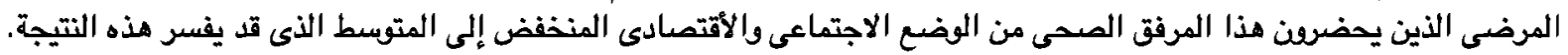

الخلاصدة: للصرع عند الأطفال تأثير كبير على نوعية حياة هؤلاء الأطفال خاصة في المجالات العاطفية والاجتماعية. بعض الأدوية المضادة

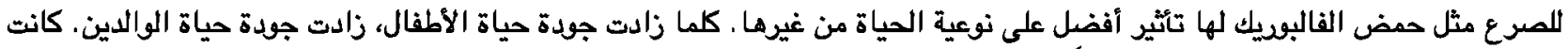

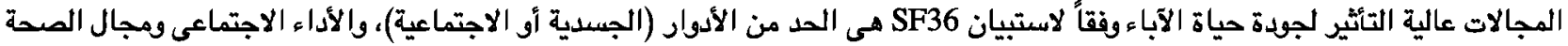

